\title{
Incidence of Valvular Regurgitation and Leaflet Perforation by Using Automated Titanium Fasteners (CORKNOT®) in Heart Valve Repair or Replacement: Less Usual than Reported
}

\section{Faizus Sazzad Sazzad}

National University of Singapore

Ong Zhi Xian

National University of Singapore

Ashlynn Ler

National University of Ireland Galway

Chang Guohao

National University Hospital Singapore

Kang Giap Swee

National University Hospital Singapore

Theo Kofidis ( $\nabla$ tkofidis@yahoo.com )

National University of Singapore https://orcid.org/0000-0002-9623-6450

Research article

Keywords: Automated Fastener, Heart Valves, Heart Valve Prosthesis, Sutures, Corknot

Posted Date: November 4th, 2020

DOl: https://doi.org/10.21203/rs.3.rs-100342/v1

License: (c) (i) This work is licensed under a Creative Commons Attribution 4.0 International License.

Read Full License

Version of Record: A version of this preprint was published at Journal of Cardiothoracic Surgery on June 7th, 2021. See the published version at https://doi.org/10.1186/s13019-021-01512-z. 


\section{Abstract}

Background: CORKNOT ${ }^{\circledR}$ facilitates a reduction in cardiopulmonary bypass (CPB) time, aortic cross clamp (ACC) time and operative time, but reported to be associated with other complications. We aim to quantify the incidence of valvular complications related to $\mathrm{CORKNOT}^{\circledR}$ and determine the feasibility of its use between different valvular surgeries.

Methods: Patients who underwent heart valve repair or replacement surgery via the use of automated titanium suture fasteners $\left(\mathrm{CORKNOT}^{\circledR}\right)$ in a tertiary care hospital were included in the study. This singlecentre retrospective study was conducted on 136 patients between January 2016 and June 2018.

Results: In our study, the mean operative time was $320.0 \pm 97.0$ min, mean CPB time was $171.4 \pm 76.0$ min and the calculated mean ACC time was $105.9 \pm 54.0$ min. 58 patients $(43.9 \%)$ underwent minimally invasive valve replacement or repair surgery and 66 patients $(50.0 \%)$ underwent concomitant procedures. A total of 157 valves were operated on, with 112 (84.8\%) single valve surgeries, 15 (11.4\%) double valve surgeries and $5(3.8 \%)$ triple valve surgeries. The incidence of moderate and/or severe paravalvular leak $(P V L)$ in immediate post-operative echocardiography was found in $7(5.3 \%)$ patients. There were no reported cases of valvular thrombosis leaflet perforation, device dislodgement or embolization during follow-up echocardiography. Single mitral valve and aortic surgeries had comparable incidences of valvular complications.

Conclusion: We conclude the feasibility of $\mathrm{CORKNOT}^{\circledR}$ utilisation in mitral and aortic valve surgeries. Additionally, incidence of $\mathrm{CORKNOT}^{\circledR}$ related complications in heart valve repair or replacement surgery is less usual in our setting than previously reported. These results motivate the use of CORKNOT $^{\circledR}$ as a valid alternative with complete commitment.

\section{Introduction}

The CORKNOT ${ }^{\circledR}$ device is an automated titanium suture fastening system used predominantly in minimally invasive cardiac surgery. The CORKNOT ${ }^{\circledR}$ device has been reputed for its benefits in terms of strength, security and reliability ${ }^{1,2}$. It is an ergonomic device that allows automatic crimping and trimming of sutures with a single squeeze. It enables suture orientation away from the valvular leaflets while allowing simultaneous suture tensioning and prosthetic cuff compression for suture security.

CORKNOT® was shown to be consistently better compared to hand-tied knot, resulting in a reduction in cardiopulmonary bypass time, aortic cross clamp time and operative time reported in minimally invasive mitral valve repair and aortic valve replacement ${ }^{3}$. Comparisons between CORKNOT ${ }^{\circledR}$ and the standard hand-tied sutures have shown that suture strength, consistency and speed to be superior ${ }^{4}$. The relative strengths of CORKNOT ${ }^{\circledR}$ are evident, but the correlation with valvular complications requires further inquiry. 
However, overall procedural time savings do come with the additional cost of the more expensive automated titanium suture fastener ${ }^{5}$. Valvular regurgitation associated with the use of CORKNOT® has also been reported ${ }^{6}$. Delayed metallic embolization of the CORKNOT ${ }^{\circledR}$ fasterner ${ }^{7}$ may also indicate the need for long-term surveillance in patients.

The surge in the popularity of CORKNOT ${ }^{\circledR}$ as an efficacious tool in supporting the rise of minimally invasive cardiac procedures warrants assessment of its risks and benefits. This study was designed to investigate the incidence of valvular complications in patients where COR-KNOT ${ }^{\circledR}$ was used and draw preliminary conclusions on the risks involved in using automated titanium suture fasteners in cardiac valve replacement and/or repair surgeries.

\section{Methods}

\section{Study participants}

This is a retrospective descriptive study approved by the Domain Specific Review Board (DSRB) under National Healthcare Group (No\# 2018/01269), Singapore. 136 patients who underwent heart valve repair or replacement surgery via automated titanium suture fasteners (CORKNOT ${ }^{\circledR}$ ) in the Department of Cardiothoracic Surgery in a tertiary care hospital between January 2016 through June 2018 were analysed. Patients who underwent single, double or triple valvular surgeries were included in the study. 132 patients met the inclusion criteria. Patients who had missing valvular surgery parameters and postoperative echocardiographic variables were excluded from the study. One patient had a sutureless prosthesis failure and required on-table revision with sutured bioprosthesis. Patients were stratified by the number of valves operated on (single vs double vs triple) and the type of valve operated on (aortic vs mitral vs tricuspid vs pulmonary). Hypothesis testing was conducted for 112 patients who underwent single aortic or mitral valve surgeries. 3 patients were excluded from the hypothesis testing due to low pulmonary and tricuspid valve case volume.

\section{Outcome Measurements and Ascertainment}

Baseline characteristics, peri-operative parameters, and follow-up parameters of patients were extracted from the local electronic database from our institute. The primary outcomes were post-operative ejection fraction, paravalvular leak, transvalvular regurgitation and valvular thrombosis assessed via postoperative echocardiography. The secondary outcomes consisted of re-interventions, cardiac mortality and all-cause mortality.

\section{Statistical Analysis}

Continuous data were presented as mean with standard deviation. Categorical data were presented as frequencies and percentages. Hypothesis testing via Chi-square test and Student's t-test were utilised for categorical and continuous variables respectively. Statistically significant variables are defined as $p<$ 
0.05. All statistical analyses were performed with IBM SPSS Statistics Version 23.0 [IBM Corporation (2015)].

\section{Results}

The final study population consisted of 132 patients who underwent heart valve replacement and/or repair procedures using CORKNOT®. Patients who had co-morbidities, active endocarditis $(15,11.4 \%)$, undergoing concomitant procedures $(66,50.0 \%)$ or had undergone cardiac surgery previously $(10,7.6 \%)$ were included in this study to improve the internal validity of the study.

Patient characteristics and peri-operative parameters of all patients Baseline characteristics of all patients are summarised in Table 1 . The patients were predominantly male $(69.4 \%)$ and Chinese $(72.4 \%)$ with a mean age of $60 \pm 12.3$ years. 
Table 1

Baseline preoperative characteristics of patients who underwent valve surgery via the use of CORKNOT®

\begin{tabular}{|c|c|c|c|c|}
\hline Characteristics & $\begin{array}{l}\text { Patients } \\
(n=132)\end{array}$ & $\begin{array}{l}\text { Single Mitral } \\
\text { Valve } \\
(n=66)\end{array}$ & $\begin{array}{l}\text { Single Aortic } \\
\text { Valve } \\
(n=43)\end{array}$ & $\begin{array}{l}\text { p- } \\
\text { value }\end{array}$ \\
\hline \multicolumn{5}{|l|}{ Demographics } \\
\hline Age - year (mean \pm SD) & $\begin{array}{l}60.1 \pm \\
12.3\end{array}$ & $57.9 \pm 11.7$ & $62.9 \pm 12.5$ & $<0.05$ \\
\hline Gender & \multirow{2}{*}{$\begin{array}{l}91 \\
(68.9 \%) \\
41 \\
(31.1 \%)\end{array}$} & $42(63.6 \%)$ & $34(79.1 \%)$ & \multirow[t]{2}{*}{0.094} \\
\hline $\begin{array}{l}\text { Male } \\
\text { Female }\end{array}$ & & $24(36.4 \%)$ & $9(20.9 \%)$ & \\
\hline Ethnicity & $\begin{array}{l}95 \\
(72.0 \%)\end{array}$ & $45(68.2 \%)$ & $32(74.4 \%)$ & \multirow[t]{5}{*}{$<0.05$} \\
\hline Chinese & $8(6.1 \%)$ & $3(4.5 \%)$ & $4(9.3 \%)$ & \\
\hline Malay & $9(6.8 \%)$ & $8(12.1 \%)$ & $1(2.3 \%)$ & \\
\hline Indian & $3(2.3 \%)$ & 0 & $3(7.0 \%)$ & \\
\hline $\begin{array}{l}\text { Caucasian } \\
\text { Others }\end{array}$ & $\begin{array}{l}17 \\
(12.9 \%)\end{array}$ & $10(15.2 \%)$ & $3(7.0 \%)$ & \\
\hline Body Surface Area $-\mathrm{m}^{2}($ mean $\pm \mathrm{SD})$ & $1.8 \pm 0.2$ & $1.76 \pm 0.23$ & $1.82 \pm 0.21$ & 0.233 \\
\hline $\begin{array}{l}\text { Pre-operative Ejection Fraction - \% } \\
\text { (mean } \pm S D)\end{array}$ & $\begin{array}{l}55.6 \pm \\
12.3\end{array}$ & $58.8 \pm 11.3$ & $52.0 \pm 13.5$ & $<0.05$ \\
\hline
\end{tabular}

\section{Co-morbidities}

\begin{tabular}{lllll} 
Stroke & $5(3.8 \%)$ & $2(4.7 \%)$ & $2(3.0 \%)$ & 0.646 \\
\hline Transient Ischemic Attack & $1(0.8 \%)$ & 0 & $1(2.3 \%)$ & 0.394 \\
\hline Congestive Cardiac Failure & 20 & $10(15.2 \%)$ & $5(11.6 \%)$ & 0.778 \\
\hline Hypertension & $(15.2 \%)$ & & & \\
\hline Hyperlipidemia & 66 & $28(42.4 \%)$ & $25(58.1 \%)$ & 0.121 \\
\hline Peripheral Arterial Disease & $(50.0 \%)$ & $30(69.8 \%)$ & $<0.05$ \\
\hline Myocardial Infarction & $\begin{array}{l}64 \\
(48.5 \%)\end{array}$ & $28(42.4 \%)$ & $3(7.0 \%)$ & 0.679 \\
\hline Diabetes & $7(5.3 \%)$ & $3(4.5 \%)$ & $6(14.0 \%)$ & 0.337 \\
\hline & $12.1 \%)$ & $5(7.6 \%)$ & $12(27.9 \%)$ & 0.493
\end{tabular}




\begin{tabular}{|c|c|c|c|c|}
\hline Characteristics & $\begin{array}{l}\text { Patients } \\
(n=132)\end{array}$ & $\begin{array}{l}\text { Single Mitral } \\
\text { Valve } \\
(n=66)\end{array}$ & $\begin{array}{l}\text { Single Aortic } \\
\text { Valve } \\
(n=43)\end{array}$ & $\begin{array}{l}\mathrm{p}- \\
\text { value }\end{array}$ \\
\hline Deep Vein Thrombosis & 0 & 0 & 0 & - \\
\hline Pulmonary Embolism & 0 & 0 & 0 & - \\
\hline Smoking & $\begin{array}{l}22 \\
(16.7 \%)\end{array}$ & $11(16.7 \%)$ & $8(18.6 \%)$ & 0.801 \\
\hline Chronic Renal Disease & $6(4.5 \%)$ & $3(6.1 \%)$ & $2(4.7 \%)$ & 1.00 \\
\hline $\begin{array}{l}\text { Creatinine Clearance }-\mathrm{ml} / \mathrm{min} \text { (mean } \pm \\
\text { SD) }\end{array}$ & $\begin{array}{l}82.8 \pm \\
24.9\end{array}$ & $85.0 \pm 23.8$ & $81.8 \pm 26.1$ & 0.521 \\
\hline Chronic Liver Disease & $1(0.8 \%)$ & 0 & 0 & - \\
\hline Chronic Lung Disease & $7(5.3 \%)$ & $1(1.5 \%)$ & $5(11.6 \%)$ & $<0.05$ \\
\hline Active Endocarditis & $\begin{array}{l}15 \\
(11.4 \%)\end{array}$ & $10(15.2 \%)$ & $3(7.0 \%)$ & 0.240 \\
\hline Previous Cardiac Surgery & $\begin{array}{l}10 \\
(7.6 \%)\end{array}$ & $3(4.5 \%)$ & $3(7.0 \%)$ & 0.679 \\
\hline Poor Mobility & $\begin{array}{l}15 \\
(11.4 \%)\end{array}$ & $7(10.6 \%)$ & $4(9.3 \%)$ & 1.00 \\
\hline
\end{tabular}

Patients who underwent single mitral valve surgery (SMV) had a lower mean age (SMV: $57.9 \pm 11.7$ vs SAV: $62.9 \pm 12.5, p<0.05$ ), higher pre-operative ejection fraction (\%) (SMV: $58.8 \pm 11.3$ vs SAV: $52 \pm 13.5$, $\mathrm{p}<0.05)$ and lower proportion of patients with hyperlipidemia (SMV: $28(42.4 \%)$ vs SAV: $30(69.8 \%), p<$ $0.05)$ and chronic lung disease. (SMV: $1(1.5 \%)$ vs SAV: $5(11.6 \%), p<0.05)$ compared to patient who underwent single aortic valve surgery (SAV). Comorbidities were comparable between both groups, except for hyperlipidemia and chronic lung disease.

Peri-operative parameters of all patients are summarised in Table 2. 58 patients (43.9\%) underwent minimally invasive valve surgery and 74 patients $(56.1 \%)$ had open heart valve surgery. Single valve surgeries were most common $(112,84.8 \%)$. Patients who underwent double valve surgery $(15,11.4 \%)$ and triple valve surgery $(5,3.8 \%)$ were few in comparison. The procedural distribution of the 157 operated valves is summarised in Fig. 1. 
Table 2

Peri-operative parameters of patients who underwent valve surgery via the use of CORKNOT ${ }^{\circledR}$

\begin{tabular}{|c|c|c|c|c|}
\hline Parameters & $\begin{array}{l}\text { Patients } \\
(n=132)\end{array}$ & $\begin{array}{l}\text { Single Mitral } \\
\text { Valve } \\
(n=66)\end{array}$ & $\begin{array}{l}\text { Single Aortic } \\
\text { Valve } \\
(n=43)\end{array}$ & $\begin{array}{l}\text { p- } \\
\text { value }\end{array}$ \\
\hline Minimally Invasive Surgery & $58(43.9 \%)$ & $39(59.1 \%)$ & $13(30.2 \%)$ & $<0.05$ \\
\hline Single Valve & $\begin{array}{l}112 \\
(84.8 \%)\end{array}$ & - & - & - \\
\hline Double Valve & $15(11.4 \%)$ & - & - & - \\
\hline Triple Valve & $5(3.8 \%)$ & - & - & - \\
\hline Concomitant procedures & $66(50.0 \%)$ & $26(39.4 \%)$ & $22(51.2 \%)$ & 0.243 \\
\hline $\begin{array}{l}\text { Operative Time }- \text { minutes (mean } \pm \\
\text { SD) }\end{array}$ & $\begin{array}{l}320.0 \pm \\
97.0\end{array}$ & $307.4 \pm 83.2$ & $311.0 \pm 94.9$ & 0.836 \\
\hline CPB Time - minutes $($ mean \pm SD) & $\begin{array}{l}171.4 \pm \\
76.0\end{array}$ & $160.5 \pm 72.1$ & $167.2 \pm 73.8$ & 0.641 \\
\hline ACC Time - minutes (mean \pm SD) & $\begin{array}{l}105.9 \pm \\
54.0\end{array}$ & $95.5 \pm 49.6$ & $111.6 \pm 58.0$ & 0.130 \\
\hline Hospital stay - days (mean \pm SD) & $\begin{array}{l}13.4 \pm \\
11.8\end{array}$ & $12.9 \pm 6.7$ & $10.5 \pm 6.0$ & 0.065 \\
\hline ICU stay - days (mean \pm SD) & $4.1 \pm 2.8$ & $3.8 \pm 1.9$ & $3.4 \pm 1.8$ & 0.246 \\
\hline $\begin{array}{l}\text { Chest Tube duration - days (mean } \pm \\
\text { SD) }\end{array}$ & $5.0 \pm 2.9$ & $4.8 \pm 1.9$ & $4.1 \pm 1.4$ & 0.05 \\
\hline
\end{tabular}

Minimally invasive approach was more prevalent in patients who underwent single mitral valve surgery (SMV: 39 (59.1\%) vs SAV: 13 (30.2\%), p < 0.05). Patients who underwent single aortic valve surgery had shorter duration of chest tube insertion (SMV: $4.8 \pm 1.9$ vs SAV: $4.1 \pm 1.4, p<0.05$ ). The proportion of concomitant procedures performed, operative time, cardiopulmonary bypass time, aortic cross clamp time, hospital stay and ICU stay were comparable between both groups.

\section{Post-operative outcomes}

Post-operative outcomes of all patients are summarised in Table 3. The degree of paravalvular leak (mild, moderate or severe) was evaluated via post-operative transesophageal echocardiography (TEE) and/or transthoracic echocardiography (TTE). 7 valves (5.3\%) were evaluated to have post-operative paravalvular leak. All-cause mortality recorded were shown to be $4(2.9 \%)$, out of which $1(0.7 \%)$ was cardiac-related. 
Table 3

Post-operative complications of patients who underwent valve surgery via the use of CORKNOT ${ }^{8}$

\begin{tabular}{|c|c|c|c|c|}
\hline Parameters & $\begin{array}{l}\text { Patients } \\
(n= \\
132)\end{array}$ & $\begin{array}{l}\text { Single Mitral } \\
\text { Valve } \\
(n=66)\end{array}$ & $\begin{array}{l}\text { Single Aortic } \\
\text { Valve } \\
(n=43)\end{array}$ & $\begin{array}{l}\mathrm{p}- \\
\text { value }\end{array}$ \\
\hline $\begin{array}{l}\text { Post-operative Moderate and/or Severe PVL } \\
(\mathrm{n}=157)\end{array}$ & $7(5.3 \%)$ & - & - & - \\
\hline Stroke & 0 & 0 & 0 & - \\
\hline Renal Failure & $\begin{array}{l}12 \\
(9.1 \%)\end{array}$ & $4(6.1 \%)$ & $2(4.7 \%)$ & 0.281 \\
\hline Atrial Fibrillation & $\begin{array}{l}44 \\
(33.3 \%)\end{array}$ & 27 (40.9\%) & $9(20.9 \%)$ & $<.05$ \\
\hline PPM Insertion & $6(9.1 \%)$ & $5(7.6 \%)$ & $3(7.0 \%)$ & 1.00 \\
\hline Bleeding/Transfusion & $\begin{array}{l}12 \\
(9.1 \%)\end{array}$ & $4(6.1 \%)$ & $2(4.7 \%)$ & 1.00 \\
\hline Thromboembolism & $1(0.8 \%)$ & 0 & 0 & - \\
\hline Re-intervention & $\begin{array}{l}11 \\
(8.3 \%)\end{array}$ & $3(4.5 \%)$ & $3(7.0 \%)$ & 0.679 \\
\hline Cardiac Mortality & $1(0.7 \%)$ & 0 & 0 & - \\
\hline All-cause Mortality & $4(2.9 \%)$ & $1(1.5 \%)$ & $2(4.7 \%)$ & 0.561 \\
\hline
\end{tabular}

Patients who underwent single mitral valve surgery had a higher incidence of new-onset atrial fibrillation (SMV: 27 (40.9\%) vs SAV: 9 (20.9\%), p < 0.05). Incidence of renal failure, permanent pacemaker insertion, bleeding events, reintervention and all-cause mortality were comparable between both groups.

\section{Follow-up outcomes}

The follow-up outcomes are summarised in Table 4. Majority of patients had follow-up between 3-6 months post-operatively. There was no incidence of valvular thrombosis, device dislodgement and/or embolization or leaflet perforation recorded during follow-up. Moderate or severe paravalvular leak was incident in 11 operated valves (7.0\%) while transvalvular regurgitation was incident in 6 operated valves (4.5\%). 
Table 4

Follow-up transoesophageal echocardiography (TEE) parameters of patients who underwent valve surgery via the use of CORKNOT ${ }^{\circledR}$

\begin{tabular}{|lllll|}
\hline Parameters & $\begin{array}{l}\text { Patients } \\
(\mathbf{n = 1 3 2})\end{array}$ & $\begin{array}{l}\text { Single Mitral Valve } \\
(\mathbf{n}=66)\end{array}$ & $\begin{array}{l}\text { Single Aortic Valve } \\
(\mathbf{n = 4 3})\end{array}$ & p-value \\
\hline $\begin{array}{l}\text { Follow-up TEE }(\mathbf{n}=\mathbf{1 5 7}) \\
\text { Moderate and/or Severe PVL }\end{array}$ & $11(7.0 \%)$ & $3(4.5 \%)$ & $6(14.0 \%)$ & 0.151 \\
\hline Ejection fraction (\%) & $52.6 \pm 10.4$ & $52.4 \pm 9.1$ & $53.7 \pm 11.6$ & 0.526 \\
\hline Thrombosis & 0 & 0 & 0 & - \\
\hline Transvalvular regurgitation & $6(4.5 \%)$ & $3(4.5 \%)$ & 0 & 0.174 \\
\hline
\end{tabular}

The mean ejection fraction (\%) was lower compared to the pre-operative baseline measurement (52.6 \pm 10.4 vs $55.6 \pm 12.3)$. There was an improvement in ejection fraction on follow-up in patients who underwent single aortic valve surgery ( $52.0 \pm 13.5$ vs $53.7 \pm 11.6)$. Overall, the incidence of paravalvular leak, transvalvular regurgitation and ejection fraction were comparable between patients who underwent single mitral valve surgery and single aortic valve surgery.

\section{Discussion}

Our study showed the feasibility of utilising $\mathrm{CORKNOT}^{\circledR}$ in both aortic and mitral valve surgeries. The incidence of paravalvular leak, transvalvular regurgitation and post-operative follow-up ejection fraction were comparable between both groups with comparable incidence with other studies. Similar conclusions regarding re-intervention, cardiac mortality and all-cause mortality both groups can be made. The difference in exposure and location of valves have proven to have minimal effect on valvular complications. The incidence of new-onset atrial fibrillation was observed to be higher in single mitral valve surgeries. However, atrial fibrillation is an expected complication of mitral valve surgeries due to the nature of valvular exposure compared to aortic valve surgery.

\section{Peri-operative parameters}

In this study, we observed a longer operative time compared to other studies. Grapow T.R. et al. ${ }^{2}$ reported a mean operation time of 203.9 minutes (SD, 31.02), a shorter duration in comparison to our study. Various concomitant procedures were performed in $50 \%$ of our patients in the study; the complexity of concomitant operations may account for the difference in operative time. Our inclusion of patients with multiple comorbidities may prompt additional intra-operative considerations to ensure optimal postoperative recovery. Variability of surgical technique and level of experience of using CORKNOT $^{\circledR}$ in our setting may contribute to this outcome.

\section{Post-operative outcome}


Moderate to severe paravalvular leak was reported to be present in the range of 3-6\% in studies done by O'Rourke et. al ${ }^{8}$, Smolka, G. ${ }^{9}$ and Kliger, C. ${ }^{10}$. Hwang H.Y. et. al. ${ }^{11}$ reported an incidence of $4.5 \%$ of postoperative paravalvular leak. These studies were comparable to our incidence of post-operative paravalvular leak. Consistent use of $\mathrm{CORKNOT}^{\circledR}$ may allow surgeons to progress through the learning curve at a quicker pace and achieve superior valvular replacement or repair outcomes.

Pinheiro C.P. et. al. ${ }^{12}$ and Hwang H.Y. et. al. ${ }^{11}$ reported institutional in-hospital mortality rates of $6.1 \%$ and $4.5 \%$ respectively, both which showed poorer outcomes in comparison to our study. Postoperative complications reported by Beute T.J. et. al. ${ }^{3}$ included 1 incident of stroke (1.9\%), 2 incidents (3.8\%) of renal failure, 17 incidents (33.0\%) of new-onset atrial fibrillation, 3 incidents (5.7\%) of permanent pacemaker insertions and 11 incidents (21.2\%) of post-operative transfusion of blood products. Except for renal failure and permanent pacemaker insertions, all reported incidences of post-operative complications were higher or comparable to our study.

\section{Follow-up outcome}

Beute T.J. et. al. ${ }^{3}$ reported a mean post-operative follow-up ejection fraction of $57.7 \%(S D, 12.2)$ in the automated titanium suture fasteners group, which was higher than the ejection fraction measured during follow-up in our study. In the same study, the mean pre-operative ejection fraction of the same group was $62 \%$. The decline in ejection fraction in the study was $4.3 \%$, comparable to the $4.0 \%$ reported in our study. The decline in ejection fraction from baseline to follow-up is therefore an expected outcome. Most reported trivial or mild paravalvular leaks were resolved during the follow-up, suggesting spontaneous resolution of paravalvular leak. However, 4 patients developed paravalvular leak between post-operative and follow-up.

The incidence of valvular regurgitation ${ }^{6}$, leaflet perforation ${ }^{13,14,15}$, paravalvular leakage ${ }^{6,16}$ and embolization ${ }^{7}$ have not been reflected in clinical trials or larger scale studies. Similarly, our study reported nil incidence of leaflet perforation with bioprosthesis or repaired heart valves. Larger-scale comparative studies will be required to elicit the true complication profile of CORKNOT ${ }^{\circledR}$.

\section{Limitations}

This is a single-centre retrospective database analysis which has relatively low case volume. Our analysis is limited to single valve comparisons between commonly operated aortic and mitral valves. Analysis of multiple valves and less commonly operated valves such as pulmonary and tricuspid valves would be less feasible in our institution. Another limitation of our study is the paucity in current literature on complications arising from the use of automated titanium suture fasteners, with most being case reports or comments.

\section{Conclusions}


With the surge and increasing preference towards minimally invasive cardiac procedures CORKNOT ${ }^{\circledR}$ may be an efficacious and facilitative tool. We have identified the feasibility in its utilisation between aortic and mitral valves. There is a potentially better outcome with the use of CORKNOT ${ }^{\circledR}$ given the low incidence of valvular complications observed and paravalvular leak compared to similar studies.

\section{Glossary Of Abbreviations}

CPB: Cardiopulmonary bypass

ACC: Aortic cross clamp

PVL: Paravalvular leak

SPSS: Statistical Package for the Social Sciences

$S M V$ : Single mitral valve surgery

SAV: Single aortic valve surgery

ICU: Intensive care unit

TEE: Transesophageal echocardiography

TTE: Transthoracic echocardiography

SD: Standard deviation

\section{Declarations}

\section{Ethics approval and consent to participate}

This is a retrospective descriptive study approved by the Domain Specific Review Board (DSRB) under National Healthcare Group (No\# 2018/01269), Singapore. Waiver of consent was applicable due to the retrospective nature of the study.

\section{Consent for publication}

Not applicable

\section{Availability of data and materials}

Deidentified research data is available on request.

\section{Competing interests}

No potential conflicts of interest with respect to the research, authorship, and publication of the article. 


\section{Funding}

The authors declare that there was no external funding provided for the present study

\section{Authors' contributions}

F.S and K.G designed the study and applied for approval. Z.X and A.L wrote the manusrcript. G.H and T.K reviewed the manuscript and made change in the manuscript. Z.X collected clinical follow- up data and analyzed data. F.S, A.L and Z.X made supplement of patients data and changed parts of K.G and T.K supervised the overall completion of the project.manuscript. All authors read and the approved the final manuscript.

\section{Acknowledgements}

The authors thank the entire participant and the nursing team of the Department of Cardiac, Thoracic \& Vascular Surgery of National University Hospital, Singapore. Special thanks were given to Mr Elgin Goh.

\section{References}

1. Perin, G., Shaw, M., Pingle, V., Palmer, K., Al-Rawi, O., Ridgway, T., \& Modi, P. (2019). Use of an automated knot fastener shortens operative times in minimally invasive mitral valve repair. The Annals of The Royal College of Surgeons of England, (0), 1-7.

2. Grapow, M. T., Mytsyk, M., Fassl, J., Etter, P., Matt, P., Eckstein, F. S., \& Reuthebuch, O. T. (2015). Automated fastener versus manually tied knots in minimally invasive mitral valve repair: impact on operation time and short-term results. Journal of cardiothoracic surgery, 10(1), 146.

3. Beute, T. J., Oram, M. D., Schiller, T. M., Goehler, M., Parker, J., Willekes, C. L., \& Timek, T. (2018). Use of an Automated Suture Fastening Device in Minimally Invasive Aortic Valve Replacement. The Annals of thoracic surgery, 106(1), 58-62.

4. Lee, C. Y., Sauer, J. S., Gorea, H. R., Martellaro, A. J., \& Knight, P. A. (2014). Comparison of strength, consistency, and speed of COR-KNOT versus manually hand-tied knots in an ex vivo minimally invasive model.Innovations, 9(2), 111-116.

5. Etiwy, M., Javadikasgari, H., Houghtaling, P., \& Gillinov, M. (2018). Automated Titanium Fasteners Versus Hand-Tied Knots: A Randomized Controlled Trial.The Annals of thoracic surgery,106(4), 11601163.

6. Brescia, A. A., Bolling, S. F., \& Patel, H. J. (2017). Valvular regurgitation after implantation of prostheses secured with Cor-Knot automated fasteners. The Annals of thoracic surgery, 103(6), e491e492.

7. Garrett Jr, H. E. (2017). Delayed Metallic Embolization of a Cor-Knot Fastener. The Thoracic and cardiovascular surgeon reports,6(01), e40-e41.

8. O’Rourke, D. J., Palac, R. T., Malenka, D. J., Marrin, C. A., Arbuckle, B. E., \& Plehn, J. F. (2001). Outcome of mild periprosthetic regurgitation detected by intraoperative transesophageal 
echocardiography.Journal of the American College of Cardiology,38(1), 163-166.

9. Smolka, G., \& Wojakowski, W. (2010). Paravalvular leak-important complication after implantation of prosthetic valve.E-journal of Cardiology Practice,9(8).

10. Kliger, C., Eiros, R., Isasti, G., Einhorn, B., Jelnin, V., Cohen, H., \& Ruiz, C. E. (2012). Review of surgical prosthetic paravalvular leaks: diagnosis and catheter-based closure.European heart journal,34(9), 638-649.

11. Hwang, H. Y., Choi, J. W., Kim, H. K., Kim, K. H., Kim, K. B., \& Ahn, H. (2015). Paravalvular leak after mitral valve replacement: 20-year follow-up. The Annals of thoracic surgery, 100(4), 1347-1352.

12. Pinheiro, C. P., Rezek, D., Costa, E. P., Carvalho, E. S. L. D., Moscoso, F. A. B., Taborga, P. R. C., ... \& Ramos, A. I. D. O. (2016). Paravalvular regurgitation: clinical outcomes in surgical and percutaneous treatments. Arquivos brasileiros de cardiologia, 107(1), 55-62.

13. Balan, R., Mogilansky, C., Larsen, A. L., \& Massoudy, P. (2017). Severe aortic regurgitation after implantation of a sutureless valve prosthesis using an automatic knot fastener device.Interactive cardiovascular and thoracic surgery,25(1), 153-154.

14. Biefer, H. R. C., Weber, A., Maisano, F., \& Benussi, S. (2018). Leaflet perforation by Cor-Knot automated fasteners: more usual than you think. The Annals of thoracic surgery, 105(2), 664-665.

15. Baciewicz Jr, F. A. (2018). Cor-Knot Perforation of Aortic Valve Leaflet. The Annals of thoracic surgery, 106(3), 936.

16. Dinesh Kumar, U. S., Nareppa, U., Shetty, S. P., \& Wali, M. (2015). Transvalvular mitral regurgitation following mitral valve replacement a diagnostic dilemma. Annals of cardiac anaesthesia, 18(4), 584-586.

\section{Figures}




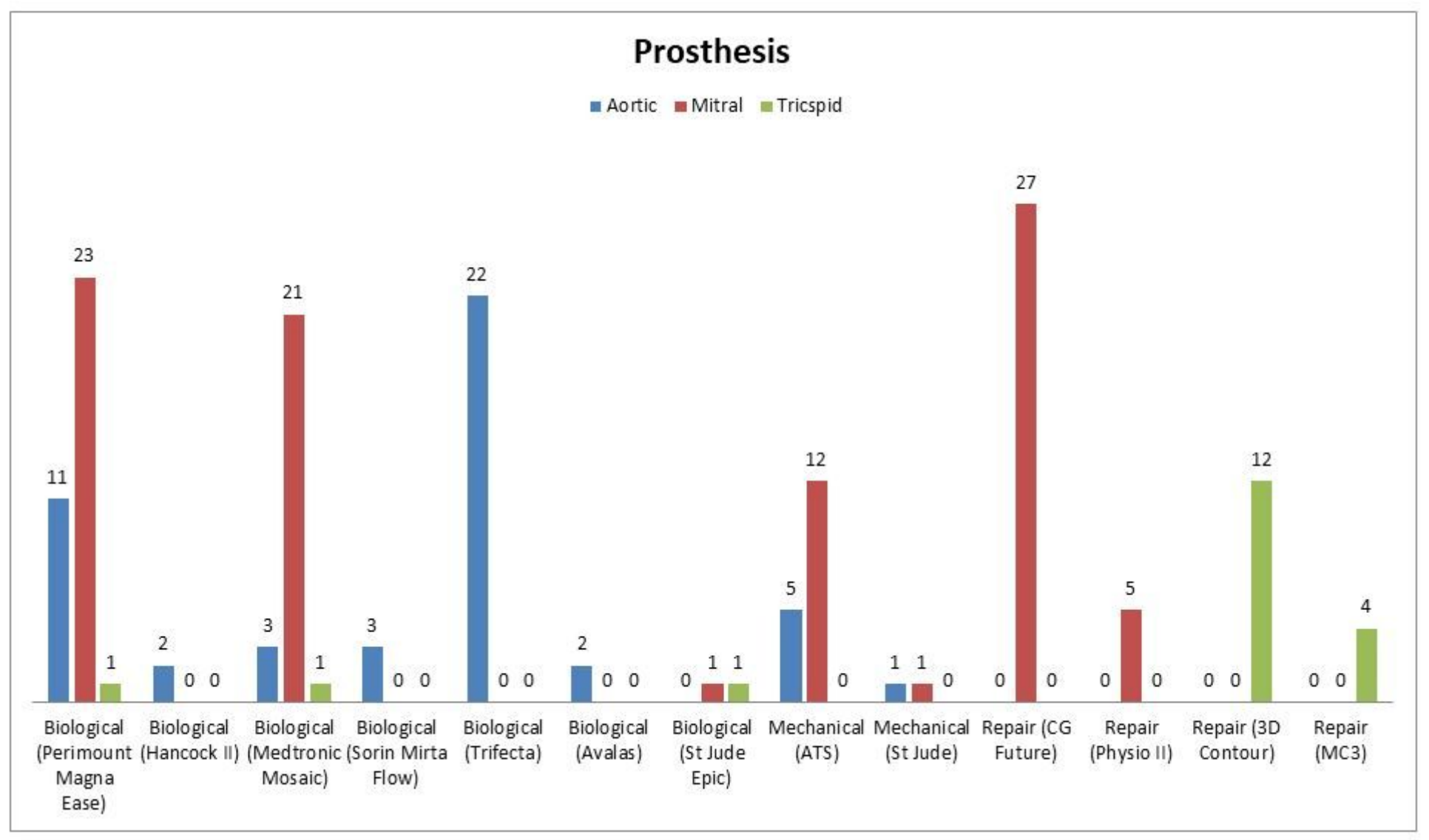

\section{Figure 1}

Distribution of prosthesis in the study population

\section{Supplementary Files}

This is a list of supplementary files associated with this preprint. Click to download.

- 4CorknotApplicationSupplimentary.docx

- 5.CorknotSupplimentaryVideo.mp4 